\title{
The Bidding Audit Method Based on Big Data
}

\author{
Moji Wei, Zijiang Yang, Shiwei Zhu and Xianyi Li \\ Information Research Institute, Qilu University of Technology (Shandong Academy of Sciences), Jinan, China
}

\begin{abstract}
With the issue of a series of important laws and regulations, the police level for violation prevention of bidding has been more and more mature. However, due to lacking effective technologies, supervision of concrete flow has become the weakness of the whole system. To perfect bidding system and enhance prior supervision, based on data analysis of bidding, this paper proposes four audit solutions which can promote early warning control on potential risks and avoid the launching of unregulated project.
\end{abstract}

Keywords—big data, bidding audit, text analysis

\section{INTRODUCTION}

Invitation to bid and bidding, which is an auction about procurement of goods, works or services, is an internationally popular trading model [1]. Usually it is tenderer prior proposes conditions and requirements of the procurement firstly, and then invites a number of bidders to compete for contract, finally in accordance with the rules and procedures selects trader [2]. The bidding plays important roles in breaking industry monopolies and regional blockades, improving economic efficiency, promoting project quality, preventing and reducing corruption, etc. [3]

In order to regulate the activities of bid invitation and bidding, safeguard the rights of the State, the social public and the parties concerned in the process of bidding, enhance the economic performance, and ensure the quality of projects, since 1999, the state has successively enacted "The Law of the People's Republic of China on Bid Invitation and Bidding”, "Regulation on the Implementation of the Bidding Law of the People's Republic of China”, “The Tendering and Bidding Law of the People's Republic of China”, and other administrative organizations have also issued a series of regulations such as "Administrative Measures for Bidding and Submission of Tendering for Construction Projects", "Provisions on the Administration of the Bidding of Investors of Commercial Highway Construction Projects", "Measures for the Administration of Bidding for Communications Construction Projects”, etc. In order to regulate electronic bidding activities, and promote the healthy development of electronic bidding, the National Development and Reform Commission, the Ministry of Industry and Information Technology, and other administrative organizations jointly formulated "Measures for Electronic Bidding” and relevant annexes, which are hereby issued, and came into force on May 1, 2013.

The "Measures for Electronic Bidding" is programmatic document for the implementation of electronic tendering and bidding in China, and is import milestone of bidding industry. It is conducive to improving procurement transparency, saving resources and transaction costs [4]. Especially it has significant advantage in offering technological support for solving fraudulent bidding, collusion between tenderer and bidder, restrain or "squeeze out" potential tenderers, and discrimination against the potential tenderers.

Theoretically the whole process of bidding has already had a sound operating procedures. However illegal bidding events are still common in practice. There are many progressive injustices occurred in bidding market, which are caused by dodging tenderers, resisting surveillance, false bidding, conspired bidding, agency illegal operation, interfering project with authority, etc. [5-8]

Government investment projects have always been the focus of supervision. Nevertheless the supervision is still not mature. It more concentrate on the legality and compliance of procedures, and the monitoring of effect is usually ignored [9, 10]. Moreover the supervision is almost after-the-event supervision rarely is prior supervision. Some serious problems in major projects are only found by audit department after completion.

With the coming era "big data", it is convenient to get requirement information from tenderers and business information from bidders [11]. Through integrating and analyzing information from distributed websites, it is possible to automatically audit the legality and compliance of procedures from multi-perspectives and detect potential problems before launching to minimize damage.

\section{BIDDING INFORMATION CAPTURE}

Various government procurement websites and bidding websites are used as target data sources, and more specifically in the websites four types of announcements which are bid invitation announcement, bid winner announcement, abandoned bid announcement and information correction announcement are used as analysis subject. The URL address list entries for four types of announcements are allocated to distributed web crawlers according to given strategy.

The contents crawled by crawlers are unstructured web pages which contain irrelevant information such as advertisements, blogrolls, similar recommendations, etc. In preprocessing filtering such irrelevant information and extracting valid information is the key to subsequent processing. In this part combining DOM tree method with block distribution function method can be used.

With preprocessing unstructured valid information can be obtained. Next accurate extraction of structured data from unstructured data is the prerequisite for subsequent processing. Considering the audit target of bidding, following structured data should be extracted from announcements, including: 
project name, project number, bid invitation time, bid submission time, bidding location, bid opening time, bid opening location, budget, procurement organization, contact person, contact information, address, agency name, agency contact person, agency contact information, agency address, purchasing content, attachment, etc. Each structure data defines an indicator, and all the indicators construct indicator list.

\section{BIDDING INFORMATION AUDIT}

\section{A. Time audit}

According to the bidding law when an organization releases a bid invitation announcement, firstly the bid submission time should be published, and the bid submission time should be at least 20 days from bid invitation time. Secondly according to the complexity of the project, the bidding-evaluation should be finished in 1 to 5 days after bid submission time, and the bidding result should be announced. Therefore the bid invitation time, bid submission time and bid opening time should be audited.

1) Audit of bid invitation time and bid submission time

As Fig. 1 shown, the audit should compare whether the bid submission time is later than bid invitation time, and whether the time difference between them is more than 19 days. It automatically gives warning information, if there is any problem arises in the audit process.

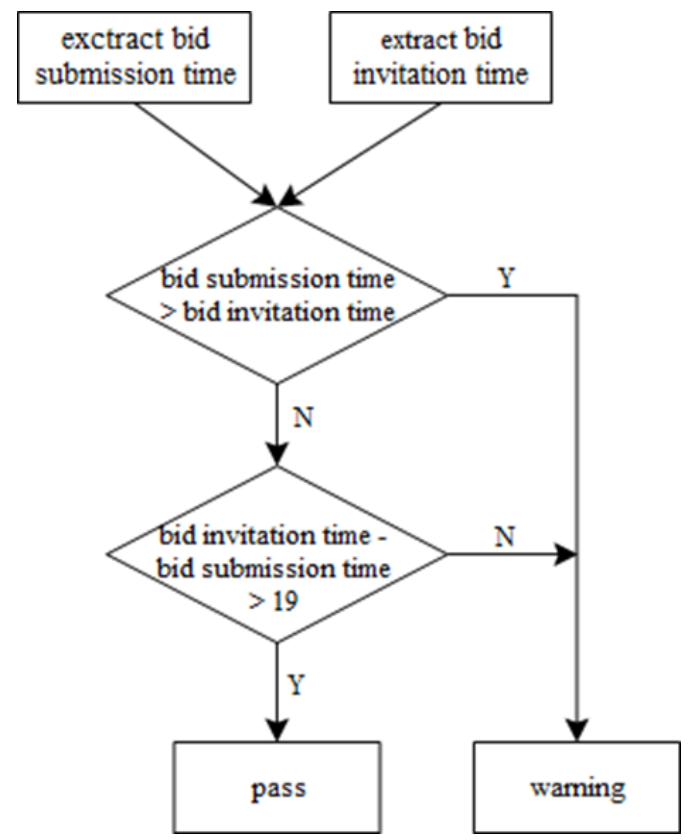

FIGURE I. AUDIT OF BID INVITATION TIME AND BID SUBMISSION TIME

2) Audit of bid opening time

As shown in Fig. 2, the audit should compare whether the bid opening time is no more than 6 days after bid submission time, or whether there is abandoned bid announcement or information correction announcement. It automatically gives warning information, if there is any problem arises in the audit process.

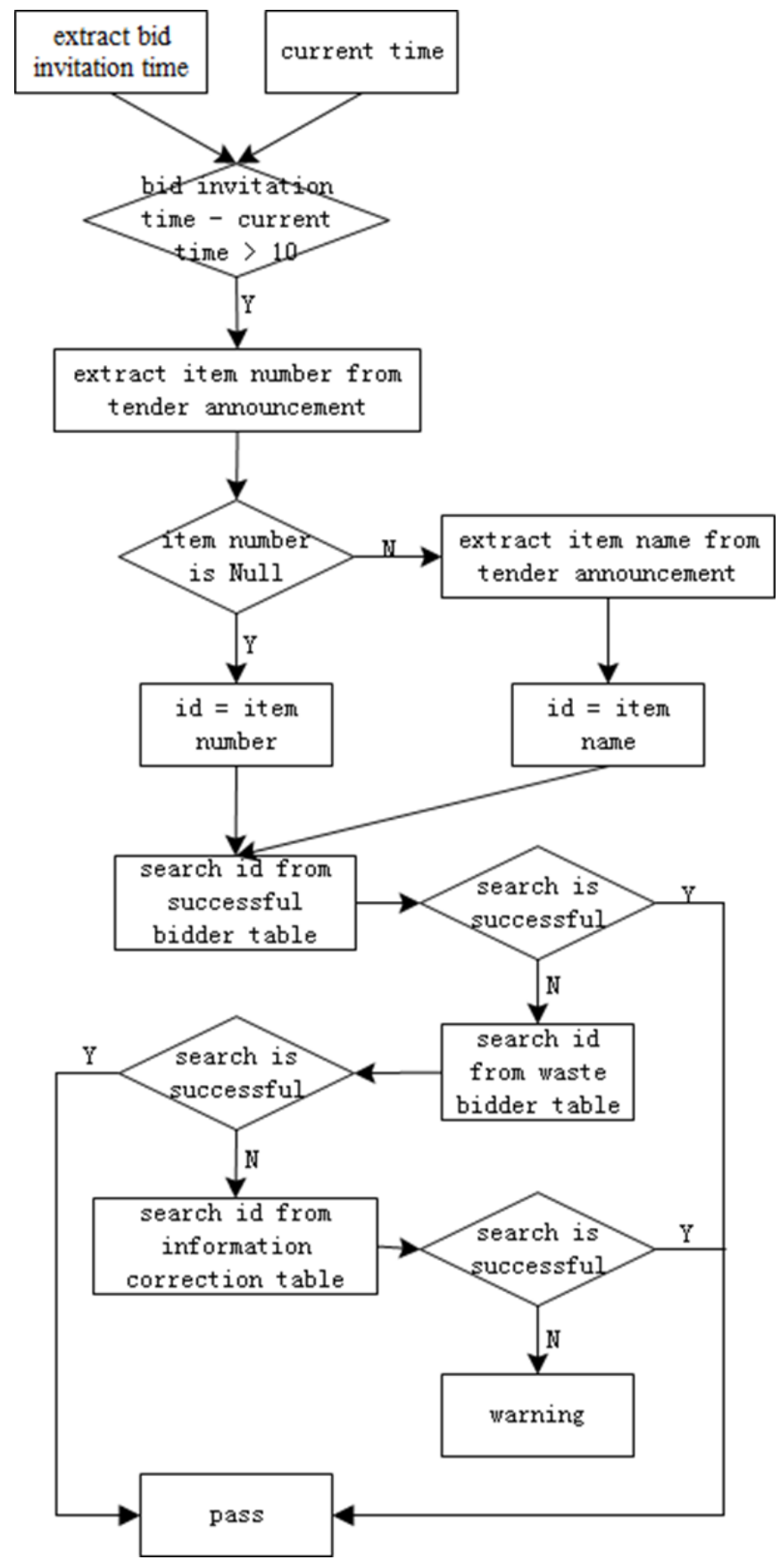

FIGURE II. AUDIT OF BID OPENING TIME

\section{B. Audit of time of winning bidder}

In order to prevent collusion between tenderer and bidder, the time of one bidder successfully getting projects from one same tender should be counted. If the time exceeds threshold, then warning information should be automatically given. Fig. 3 shows the process of audit. 


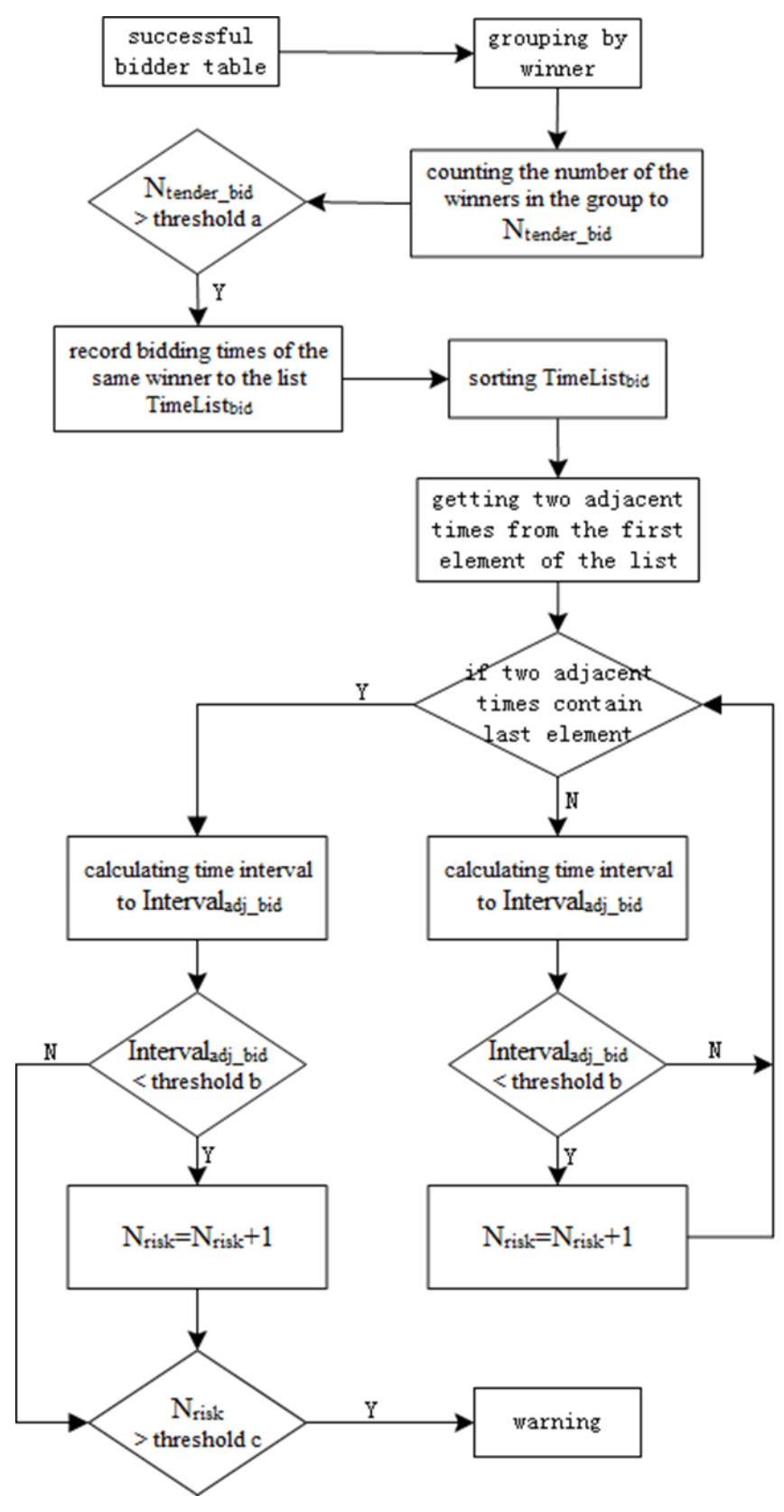

FIGURE III. AUDIT OF TIME OF WINNING BIDDER

\section{Audit of qualification}

If the tender is government, the winning bidder should have administrative qualification. Therefore it is necessary to check whether the winning bidder has administrative qualification or not. Fig. 4 shows the process of audit.

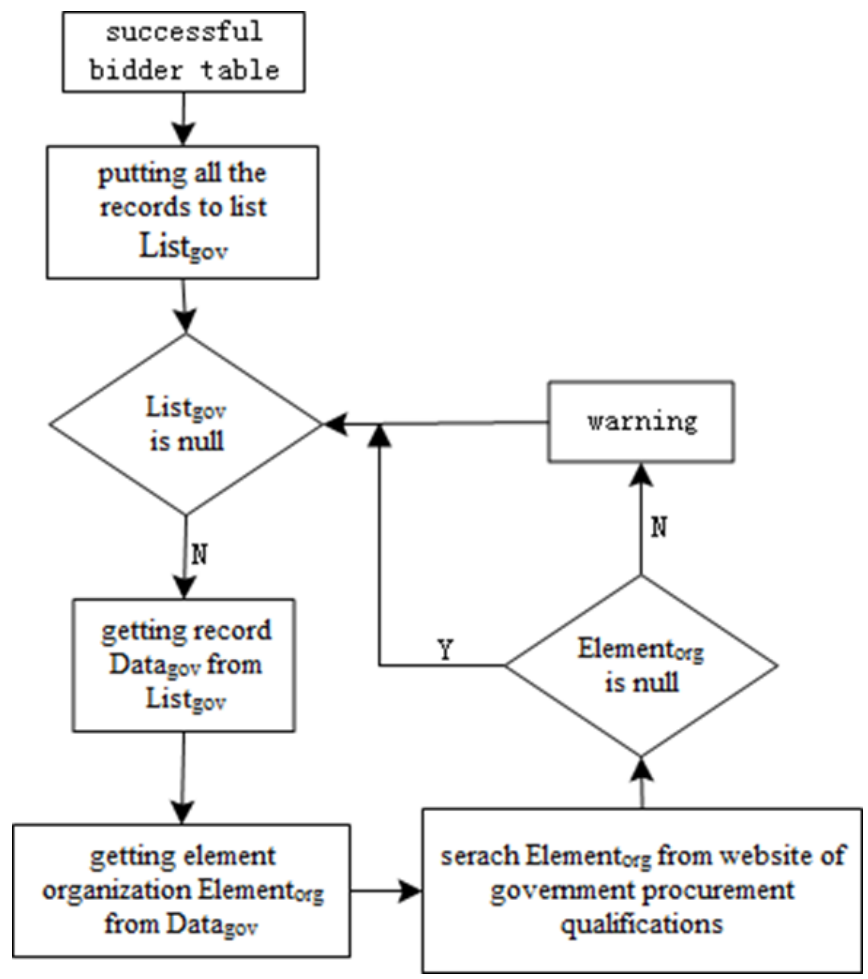

FIGURE IV. AUDIT OF QUALIFICATION

\section{Audit of procurement and business scope}

The procurements needed by tenderer should be the products that can be provided by the bidder. That means the procurement and the product should be the same kind goods. On the one hand the procurements can be explicitly obtained from the bid invitation/winner announcement. On the other hand what kind of products that bidder can provide is unknown from the announcement. Fortunately, the business scope which implicitly represents the products provided by a company can be obtained from Internet. Even so, the procurement gotten from announcement and the business scope obtained from Internet cannot be compared directly. Because the procurements are usually concrete objects or services, the business scope is generally macroscopic description of industry, and the texts used for the procurements and the business scope are quite different from each other. It is hardly get accurate result by any document similarity measure algorithm.

In order to get the consistence between procurements and business scope, the following method is proposed. The whole process of audit is shown as fig. 5 .

\section{1) Establish classification catalogue}

In order to unify classification standard for procurement and business scope, a classification catalogue which contains 57 types such as automobile service, international trade, mechanics, software development, etc. is established according to the classification set formulated by China Industrial and Commercial Bureau. 


\section{2) Construct classification model for procurement}

Select a classification algorithm, which can be Bayesian, decision tree, Support Vector Machines or others, to construct classification model for procurement. In the construction, the description of procurement and attachment documents are used as classification samples.

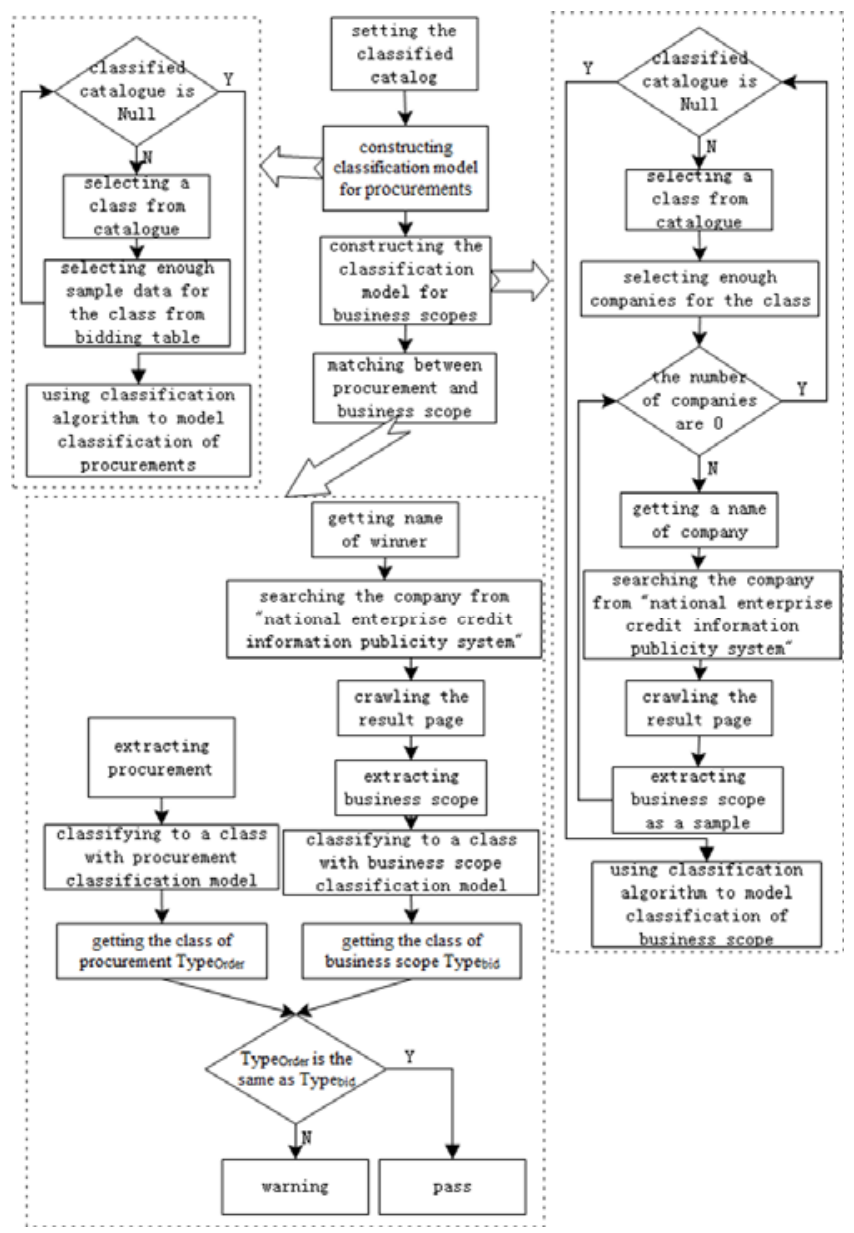

FIGURE V. AUDIT OF PROCUREMENT AND BUSINESS SCOPE

\section{3) Construct classification model for business scope}

Similar as procurement classification model construction, select a classification algorithm, which can be Bayesian, decision tree, Support Vector Machines or others, to construct classification model for business scope. In the construction, firstly choose sufficient enterprises for each type in the classification catalogue, then use enterprise name as keyword and search information from the platform of the National Enterprise Credit Information Publicity System of the State Administration for Industry \& Commerce of the People's Republic of China (SAIC), finally use the information crawled from retrieval result as classification samples to construct model for business scope.

\section{4) Compare the types between procurement and business} scope

For a new bid winner announcement, firstly extract the description of procurement and attachment documents and use the classification model for procurement to obtain the type. Then extract the enterprise name, search it from the platform of SAIC and use the classification model for business scope for the retrieval result to obtain the type. Finally match the procurement type and the business scope type, if mismatched, automatically give warning information.

\section{CONCLUSION}

Based on information analysis of invitation to bid and bidding, a bidding audit method is proposed. With audits of time, times of bid winning, qualification, and match between procurement and business scope, it can detect the potential problems earlier and alter automatically.

\section{ACKNOWLEDGMENT}

This work is financially supported by the key research and development program of Shandong province (Grant No.2016GGX101018, No. 2017GGX10118).

\section{REFERENCES}

[1] Byrd J W, Hickman K A. Do outside directors monitor managers?: Evidence from tender offer bids[J]. Journal of financial economics, 1992, 32(2): 195-221.

[2] Healy P M, Palepu K G, Ruback R S. Does corporate performance improve after mergers?[J]. Journal of financial economics, 1992, 31(2): 135-175.

[3] Johnstone K M, Bedard J C, Ettredge M L. The effect of competitive bidding on engagement planning and pricing $[\mathrm{J}]$. Contemporary Accounting Research, 2004, 21(1): 25-53.

[4] Breuer C, Moser A. Optimized bidding area delimitations and their impact on electricity markets and congestion management[C]//European Energy Market (EEM), 2014 11th International Conference on the. IEEE, 2014: 1-5.

[5] Boehm F, Olaya J. Corruption in public contracting auctions: the role of transparency in bidding processes[J]. Annals of Public and Cooperative Economics, 2006, 77(4): 431-452.

[6] Menezes F M, Monteiro P K. Corruption and auctions[J]. Journal of Mathematical Economics, 2006, 42(1): 97-108.

[7] Arozamena L, Weinschelbaum F. The effect of corruption on bidding behavior in first-price auctions[J]. European Economic Review, 2009, 53(6): 645-657.

[8] Fazekas M, Kocsis G. Uncovering high-level corruption: cross-national objective corruption risk indicators using public procurement data[J]. British Journal of Political Science, 2017: 1-10.

[9] Zhang B, Le Y, Wang Y, and Li Y. Tendering and bidding corruption research based on B2G guanxi-Based on 90 typical cases[J]. J. Public Administration, 2015, 8(1): 141-163.

[10] Zhang B, Le Y, Xia B, and Skitmore M. Causes of business-togovernment corruption in the tendering process in China[J]. Journal of Management in Engineering, 2016, 33(2): 05016022.

[11] Zhanmin Z, Xiaoxia N, Dongguo L, et al. Application of big data in electronic bidding[C]//Big Data Analysis (ICBDA), 2017 IEEE 2nd International Conference on. IEEE, 2017: 452-455. 